\title{
Thrombolytic therapy during resuscitation for pulmonary embolism-related out-of- hospital cardiac arrest: perhaps not the ideal solution for everyone
}

\author{
Patrick M. Honore*, Cristina David, Aude Mugisha, Rachid Attou, Sebastien Redant, Andrea Gallerani and \\ David De Bels
}

Javaudin et al. [1] recommended that for cases of out-ofhospital cardiac arrest (OHCA) for which a cause is not obvious, pulmonary embolism (PE) should be suspected if the initial rhythm is nonshockable and there is a history of thromboembolism (TE). In accordance with the guidelines of the American Heart Association, these patients could be treated with systemic thrombolysis (ST) during resuscitation (low level of evidence) [1]. We would like to add some comments. First, recent studies have shown that ultrasound-facilitated catheter fibrinolysis relieves right ventricular pressure overload with a lower risk of major bleeding and intracranial hemorrhage than historical rates with ST [2]. However, further research is required to determine the optimal application of this technique in the setting of acute PE [2]. Second, the insertion of an emergency veno-arterial extracorporeal membrane oxygenation (VA-ECMO) catheter should be considered before starting ST. VA-ECMO can be a lifesaving therapeutic consideration, either as an adjunct to definitive management strategies (surgical/catheter embolectomy, thrombolysis) or on its own [3]. According to a recent systematic review, VAECMO for selected patients with massive PE is associated with good outcome [3].

Third, after failure of thrombolysis, surgical embolectomy or catheter embolectomy should be considered in selected centers [3]. Fourth, published cases of thrombolysis for massive PE during pregnancy and the postpartum

\footnotetext{
* Correspondence: Patrick.Honore@CHU-Brugmann.be

This comment refers to the article available at https://doi.org/10.1186/ s13054-019-2672-6

ICU Department, Centre Hospitalier Universitaire Brugmann-Brugmann University Hospital, Place Van Gehuchtenplein, 4, 1020 Brussels, Belgium
}

period suggest acceptable maternal and fetal survival even with CA [4]. In the postpartum period, given the high risk of major bleeding with thrombolysis, other therapeutic options (catheter or surgical thrombectomy, VA-ECMO) should be considered if available [4]. Lastly, chronic thromboembolic pulmonary hypertension $(\mathrm{CTEPH})$ is a pulmonary vascular disease caused by chronic obstruction of major pulmonary arteries and often occurs after an initial PE or TE [5]. The authors note the importance of a past history of PE or TE as a risk factor and should therefore consider CTEPH as well. CTEPH can be cured by pulmonary endarterectomy (PEA), a challenging procedure for which patient selection and perioperative management are complex, requiring significant experience [5]. We had a 45-year-old patient with CTEPH who, after failed thrombolysis, was transferred to another center for PEA and achieved a full recovery [5]. Thrombolysis may not be the cure for everyone. A clear step by step approach should be considered in case of failed thrombolysis.

\section{Abbreviations \\ OHCA: Out-of-hospital cardiac arrest; PE: Pulmonary embolism; CA: Cardiac arrest; TE: Thromboembolism; ST: Systemic thrombolysis; VA-ECMO: Veno- arterial extracorporeal membrane oxygenation; CTEPH: Chronic \\ thromboembolic pulmonary hypertension; PEA: Pulmonary endarterectomy \\ Acknowledgements \\ We would like to thank Dr. Melissa Jackson for critical review of the manuscript.}

\section{Authors' contributions}

$\mathrm{PMH}, \mathrm{SR}$, and DDB designed the paper. All authors participated in drafting the manuscript. All authors have read and approved the final version.

Funding

None. 
Availability of data and materials

Not applicable.

Ethics approval and consent to participate

Not applicable.

\section{Consent for publication}

Not applicable.

\section{Competing interests}

The authors declare that they have no competing interests.

Received: 10 February 2020 Accepted: 19 February 2020

Published online: 24 February 2020

\section{References}

1. Javaudin F, Lascarrou JB, Esquina $H$, Baert V, Hubert $H$, Leclère B, GR-RéAC. Improving identification of pulmonary embolism-related out-of-hospital cardiac arrest to optimize thrombolytic therapy during resuscitation. Crit Care. 2019;23(1):409. https://doi.org/10.1186/s13054-019-2672-6 No abstract available.

2. Chopard R, Ecarnot F, Meneveau N. Catheter-directed therapy for acute pulmonary embolism: navigating gaps in the evidence. Eur Heart J Suppl. 2019;21(Suppl I):I23-30. https://doi.org/10.1093/eurheartj/suz224 Epub 2019 Nov 21

3. Yusuff $\mathrm{HO}$, Zochios V, Vuylsteke A. Extracorporeal membrane oxygenation in acute massive pulmonary embolism: a systematic review. Perfusion. 2015; 30(8):611-6. https://doi.org/10.1177/0267659115583377 Epub 2015 Apr 24

4. Martillotti G, Boehlen F, Robert-Ebadi H, Jastrow N, Righini M, Blondon M. Treatment options for severe pulmonary embolism during pregnancy and the postpartum period: a systematic review. J Thromb Haemost 2017;15(10): 1942-1950. doi: https://doi.org/10.1111/jth.13802. Epub 2017 Sep 12.

5. Segel MJ, Kogan A, Preissman S, Agmon-Levin N, Lubetsky A, Fefer P, Schaefers $H$, Raanani E. Pulmonary endarterectomy surgery for chronic thromboembolic pulmonary hypertension: a small-volume national referral center experience.lsr Med Assoc J. <https://www.ncbi.nlm.nih.gov/pubmed/?term=Segel+MJ\%2C+ Kogan+A\%2C+Preissman+S\%2C\#> 2019;21(8):528-531.

\section{Publisher's Note}

Springer Nature remains neutral with regard to jurisdictional claims in published maps and institutional affiliations. 